Research Article

\title{
Determination of Mapping Relation between Wheel Polygonalisation and Wheel/Rail Contact Force for Railway Freight Wagon Using Dynamic Simulation
}

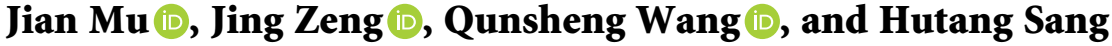 \\ State Key Laboratory of Traction Power, Southwest Jiaotong University, Chengdu, 610031, China \\ Correspondence should be addressed to Jing Zeng; zeng@swjtu.edu.cn
}

Received 8 April 2021; Accepted 12 September 2021; Published 7 October 2021

Academic Editor: Davood Younesian

Copyright ( 2021 Jian Mu et al. This is an open access article distributed under the Creative Commons Attribution License, which permits unrestricted use, distribution, and reproduction in any medium, provided the original work is properly cited.

\begin{abstract}
The polygonal wear around the wheel circumference could pose highly adverse influences on the wheel/rail interactions and thereby the performance of the vehicle system. In this study, the effects of wheel polygonalisation on the dynamic responses of a freight wagon are investigated through development and simulations of a comprehensive coupled vehicle-track dynamic model. The model integrates flexible ballasted track and wheelsets subsystem models so as to account for elastic deformations caused by impact loads induced by the wheel polygonalisation. Subsequently, the vehicles with low-order polygonal wear, whether in empty or loaded conditions, are simulated at different speeds considering different amplitudes and harmonic orders of the wheel polygonalisation and thus the mapping relation between wheel/rail impact force and wheel polygonalisation is obtained. The results reveal that the low-order wheel polygonalisation except $1^{\text {st }}$ order and $3^{\text {rd }}$ order can give rise to high-frequency impact loads at the wheel/rail interface and excite $1^{\text {st }}$-bend modes of the wheelset and "P2 resonance" leading to high-magnitude wheel/rail contact force at the corresponding speed.
\end{abstract}

\section{Introduction}

Wheel polygonalisation is a form of wheel circumferential uneven wear, also referred to as wheel polygonalisation or wheel corrugation, which generally exists in vehicles [1]. The periodic circumferential wear has been associated with high magnitudes of high-frequency impact loads at the wheel/rail interface, which contribute to undesired dynamic responses and reduced fatigue lives of the vehicle-track substructures, especially with higher axle loads and high-speed operations [2].

Owing to highly adverse effects of wheel polygonalisation, considerable efforts have been made to understand the mechanisms leading to periodic circumferential defects in railway wheels. Wheel polygonalisation was initially observed in European railways [3]. The studies suggested that wheel polygonalisation is strongly related to bending vibration of the wheelset, track properties, and dynamic unbalances in wheels. Nielsen et al. $[4,5]$ presented a comprehensive review of different types of wheel defects together with associated potential wear mechanisms and the resulting influences on dynamic responses of the vehicle. The study also proposed the wheel removal criterion in the presence of polygonalisation deformities. The influences of wheel out-of-roundness were also reviewed by Barke and Chiu [6] including the wheel/rail impacts, rail fatigue, rail joint deterioration, sleeper degradation, and noise generation. Liu and Zhai [7] investigated vertical dynamic wheel/rail interaction resulting from two types of out-of-round wheels at high speeds by a vertical vehicletrack coupled dynamics model. The results demonstrate the influence of the out-of-round wheel on vehicle system is mainly related to the wheelset vibration and derivative of wheel radial deviations can effectively reflect dynamic wheel/rail contact force.

A few studies have shown that high-magnitude impact loads could excite different bending and torsional deformation modes of the wheelset [8], which could cause higher 
lateral slippage of the wheel and wheel/rail material excavation, and thereby enlargement of out-of-round (OOR) deformities. Jin and his research team [9, 10] experimentally investigated the effects and growth of polygonal wear of subway wheels and concluded that the ninth-order polygonal wear observed in wheel deformations was due to the first bending mode of the wheelset. The effects of wheel polygonalisation on the dynamic responses of a high-speed rail vehicle are investigated through development and simulations of a comprehensive coupled vehicle-track dynamic model by $\mathrm{Wu}$ [11]. The results suggested that the high-order wheel polygonalisation could give rise to highfrequency impact loads at the wheel/rail interface and excited some of the vibration modes of the wheelset leading to high-magnitude axle box acceleration and dynamic stress in the wheelset axle. The effects of the wheel polygonization on the fatigue damage of the gearbox housing of a high-speed train are investigated through a multibody system (MBS) railway vehicle model by $\mathrm{Wu}$ [12]. The results stated that the fatigue damage with a 20th-order polygonal wear is $63 \%$ larger than that without the polygonal wear on the wheel. Moreover, the torsional vibration of the gear transmission system [13] and wheel/rail noise [14] are also affected by wheel polygonization. However, almost all of the research focuses on single order wheel polygonalisation obtained in high-speed vehicles or subways.

Wheel polygonalisation is common in freight wagon and its wear depth changes exponentially with time [15]. It is important to establish the mapping relationship detecting wheel polygonalisation by the trackside detection for freight wagon condition repair. In this study, a comprehensive coupled vehicle-track dynamic model of freight wagon is established so as to investigate the effects of low-order wheel polygonalisation on wheel/rail contact force. The model integrates flexible ballasted track and wheelset subsystem models so as to account for elastic deformations that may occur in the presence of repetitive impact loads induced by the wheel polygonalisation at the wheel/rail interface. The effects of amplitude and harmonic order of wheel polygonal wear are subsequently investigated and the corresponding mapping relations are obtained to detect polygonal wheel by trackside detection.

\section{Establishment of Vehicle-Track Model}

A comprehensive model of a top open wagon vehicle-track system is formulated through integration of models of flexible wheelsets, a ballasted track, and the freight wagon. Figure 1 illustrates the simulation scheme comprising finite element (FE) models of the flexible wheelset and the ballasted track coupled with the open wagon model in the SIMPACK platform [11]. The FE model of the wheelset is used to determine its modal properties via the eigen analysis. The modal vectors are subsequently integrated to the wagon model using the finite element multibody systems (FEMBS) interface available in SIMPACK [11]. The resulting dynamic wheel/rail contact forces, the displacement of contact spot, and speed are obtained to serve as excitations to the ballasted track model to evaluate the deflection response of the track. The rail deflection response is subsequently integrated to the vehicle model using the SIMAT (SIMPACK-MATLAB) cosimulation interface, as shown in Figure 1, to study its dynamic responses in the presence of a wheel polygonal wear. In simulation, the track deflection is solved by a new fast numerical integration method [16] with the step size of $0.0001 \mathrm{~s}$. The component models' formulations are described in the following subsections.

2.1. Flexible Wheelset Model. The FE model of wheelset is discretized into 22066 Solid 185 elements, as shown in Figure 1. The modal characteristics of wheelset are obtained through eigen analysis. The substructure method is introduced to deal with the wheelset FE model to speed up the dynamic calculation, and the model DOF is transformed into the structural model represented by the master DOF. The nodes DOF where the force is applied or output and the boundary conditions are calculated is defined as the master DOF and the other defined as the slave DOF. The substructure method is based on Guyan reduction method condensing a set of elements into a superelement by matrix transformation [17]. The dynamic equation of the FE model can be expressed as

$$
\mathbf{M u}+\mathbf{D} \dot{\mathbf{u}}+\mathbf{K u}=\mathbf{F},
$$

where $\mathbf{M}, \mathbf{K}$, and $\mathbf{D}$ are mass matrix, stiffness matrix, and damping matrix, respectively; $\mathbf{u}$ is displacement matrix; and F is load matrix. Assuming that there are $m$ master DOF and $s$ slave DOF, the matrix form of (1) can be expressed as

$$
\begin{aligned}
& {\left[\begin{array}{cc}
\mathbf{M}_{\mathrm{mm}} & \mathbf{M}_{\mathrm{ms}} \\
\mathbf{M}_{\mathrm{sm}} & \mathbf{M}_{\mathrm{ss}}
\end{array}\right]\left[\begin{array}{c}
\ddot{\mathbf{u}}_{\mathrm{mm}} \\
\ddot{\mathbf{u}}_{\mathrm{ss}}
\end{array}\right]+\left[\begin{array}{cc}
\mathbf{D}_{\mathrm{mm}} & \mathbf{D}_{\mathrm{ms}} \\
\mathbf{D}_{\mathrm{sm}} & \mathbf{D}_{\mathrm{ss}}
\end{array}\right]\left[\begin{array}{c}
\dot{\mathbf{u}}_{\mathrm{mm}} \\
\dot{\mathbf{u}}_{\mathrm{ss}}
\end{array}\right]} \\
& +\left[\begin{array}{cc}
\mathbf{K}_{\mathrm{mm}} & \mathbf{K}_{\mathrm{ms}} \\
\mathbf{K}_{\mathrm{sm}} & \mathbf{K}_{\mathrm{ss}}
\end{array}\right]\left[\begin{array}{c}
\mathbf{u}_{\mathrm{mm}} \\
\mathbf{u}_{\mathrm{ss}}
\end{array}\right]=\left[\begin{array}{c}
\mathbf{F}_{\mathrm{mm}} \\
0
\end{array}\right]
\end{aligned}
$$

where $\mathbf{K}_{\mathrm{mm}}, \mathbf{K}_{\mathrm{ms}}, \mathbf{K}_{\mathrm{sm}}$, and $\mathbf{K}_{\mathrm{ss}}$ are $m \times m, m \times m, s \times m$, and $s \times s$ stiffness matrices, respectively; $\mathbf{M}$ and $\mathbf{D}$ are the corresponding mass and damping matrices; and $\boldsymbol{F}_{\mathrm{mm}}$ is the load vector acting on the master DOF. Considering that Guyan reduction theory is based on the static transformation of $\mathbf{K u}=\mathbf{F}[18], \mathbf{u}_{\text {ss }}$ can be assumed as

$$
\mathbf{u}_{\mathrm{ss}}=-\mathbf{K}_{\mathrm{s}}^{-1} \mathbf{K}_{\mathrm{sm}} \mathbf{u}_{\mathrm{mm}} .
$$

Thus,

$$
\mathbf{u}=\left[\begin{array}{c}
\mathbf{u}_{\mathrm{mm}} \\
\mathbf{u}_{\mathrm{ss}}
\end{array}\right]=\left[\begin{array}{c}
\mathbf{I} \\
-\mathbf{K}_{\mathrm{ss}}^{-1} \mathbf{K}_{\mathrm{sm}}
\end{array}\right] u_{\mathrm{mm}} .
$$

The DOF conversion matrix can be defined as

$$
\mathbf{T}=\left[\begin{array}{c}
\mathbf{I} \\
-\mathbf{K}_{s s}^{-1} \mathbf{K}_{\mathrm{sm}}
\end{array}\right] \text {. }
$$

Substituting (4) and (5) into equation (1), the motion equation of the finite element model with reduced degrees of freedom is 


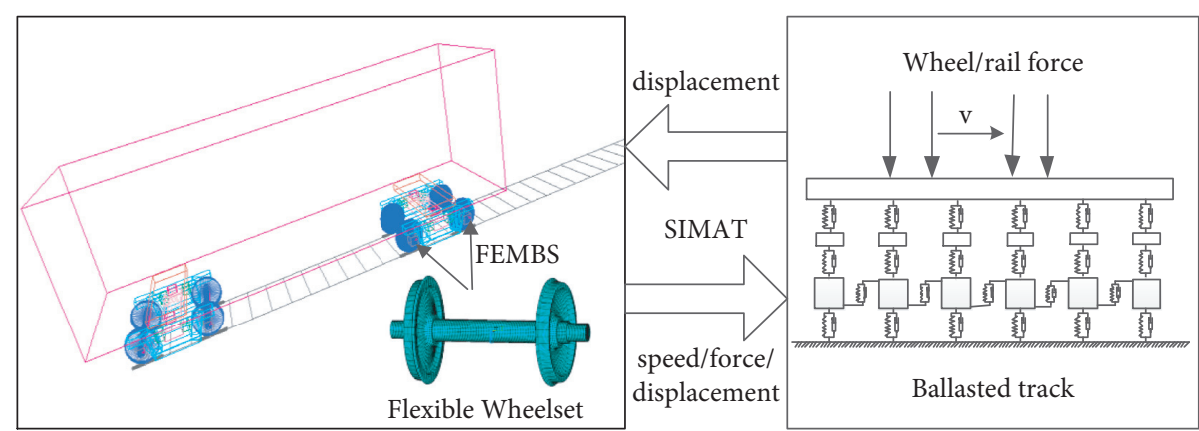

FIgURE 1: Vehicle-track dynamic system model. FEMBS: finite element multibody systems.

$$
\mathbf{M}_{\mathrm{mm}}^{*} \ddot{\mathbf{u}}_{\mathrm{mm}}+\mathbf{D}_{\mathrm{mm}}^{*} \dot{\mathbf{u}}_{\mathrm{mm}}+\mathbf{K}_{\mathrm{mm}}^{*} \mathbf{u}=\mathbf{F}^{*}
$$

where

$$
\left\{\begin{array}{l}
\mathbf{M}_{\mathrm{mm}}^{*}=\mathbf{T}^{T} \mathbf{M T}, \\
\mathbf{D}_{\mathrm{mm}}^{*}=\mathbf{T}^{T} \mathbf{D T}, \\
\mathbf{K}_{\mathrm{mm}}^{*}=\mathbf{T}^{T} \mathbf{K T}, \\
\mathbf{F}_{\mathrm{mm}}^{*}=\mathbf{T}^{T} \mathbf{F} .
\end{array}\right.
$$

The selected master DOF must retain the structural features of the components, as well as the master nodes such as hinge points and force action points. For this purpose, a total of 132 master nodes located on 13 cross sections of the wheelset along the axle direction are selected. Each of the wheel and axle end has 2 cross-sections. Additional 5 cross-sections are selected on the axle between the wheels. Considering that the wheel/rail impact force induced by wheel polygonal wear can excite some modes of the wheelset, a total of 3 vibration modes with frequency up to $229 \mathrm{~Hz}$ are considered to determine the wheelset response and 3 modes of the wheelset are shown in Figure 2.
2.2. The Ballasted Track Model. Figure 3 illustrates the ballasted track is composed of rail, fasteners, sleepers, and ballast. The rail is represented by a finite length continuous Timoshenko beam discretely supported on ballast, which is represented by mass block connected by spring-damping element, via fasteners. The model is formulated for the $100 \mathrm{~m}$ rail with the sleeper bay of $0.625 \mathrm{~m}$, which is considered to represent characteristics of the infinite length rail with reasonable accuracy and computational efficiency [19].

Both ends of the rail are assumed to be fixed, while each rail is subject to moving loads attributed to the lateral and vertical wheel/rail contact forces, $F_{w r y j}(t)$ and $F_{w r z j}(t)$ $(j=1 \sim 4)$. The lateral and vertical forces due to discrete supports are represented as $F_{s y i}(t), F_{s z i}(t)(i=1 \sim \mathrm{Ns})$, where Ns is the number of supports. Figure 3(c) also illustrates the moments caused by the wheel/rail contact forces $M_{G j}(t)$ $(j=1 \sim 4)$ and the support forces $M_{s i}(t)(i=1 \sim \mathrm{Ns})$, which are taken about the center of the rail. $x_{w j}(j=1 \sim 4)$ and $x_{s i}(i=1 \sim \mathrm{Ns})$ define the position of each wheel and the $i$ th discrete support along the rail, respectively.

The governing equations describing the vertical $z$ and bending $\Psi_{y}$ deflections of the rail subjected to vertical wheel/ rail contact forces $F_{w r z j}$ and support forces $F_{s z i}$ are obtained as [20]

$$
\left\{\begin{array}{l}
\rho A_{r} \frac{\partial^{2} z(x, t)}{\partial t^{2}}+\kappa_{z} G A_{r}\left[\frac{\partial \psi_{y}(x, y)}{\partial x}-\frac{\partial^{2} z(x, t)}{\partial x^{2}}\right]=-\sum_{i=1}^{N s} F_{s z i}(t) \delta\left(x-x_{s i}\right)+\sum_{j=1}^{N w} F_{w r z j}(t) \delta\left(x-x_{w j}\right) \\
\rho I_{y} \frac{\partial^{2} \psi_{y}(x, t)}{\partial t^{2}}+\kappa_{z} G A_{r}\left[\psi_{y}(x, t)-\frac{\partial z(x, t)}{\partial x}\right]-E I_{y} \frac{\partial^{2} \psi_{y}(x, t)}{\partial x^{2}}=0
\end{array}\right.
$$

where $\rho$ is the mass density, $A_{r}$ is the rail cross-sectional area, $G$ is the shear modulus, $E$ is Young's modulus, and $I_{y}$ is the second moment of area of the rail cross-section about the $y$-axis. In the above equations, $\kappa_{z}$ is the vertical shear coefficient, $\kappa_{z}=0.5329$. $\delta(x)$ is the Dirac delta function, and $N_{w}$ is the number of wheelset considered in the model.

Similarly, the governing equations describing the lateral $y$ and yaw $\Psi_{z}$ deflections of the rail subjected to lateral wheel/ rail contact forces $F_{w r y j}$ and support forces $F_{s y i}$ are 


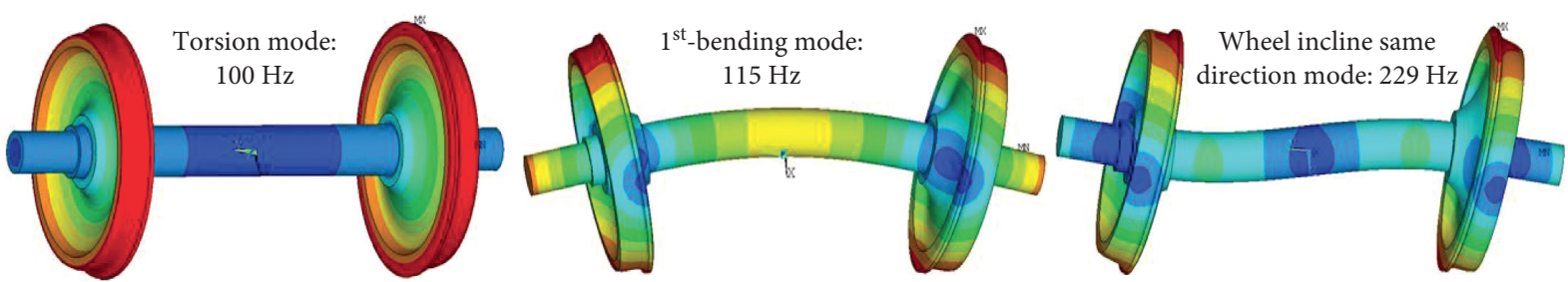

FIgURE 2: Selected vibration modes of the wheelset.

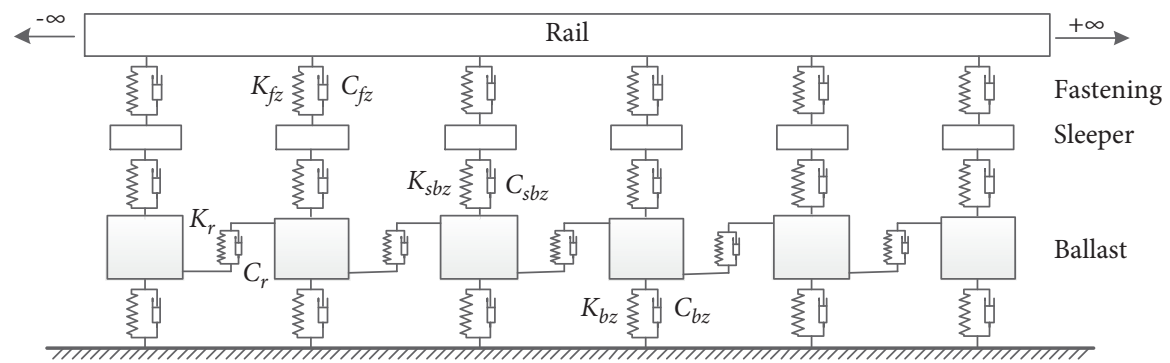

(a)

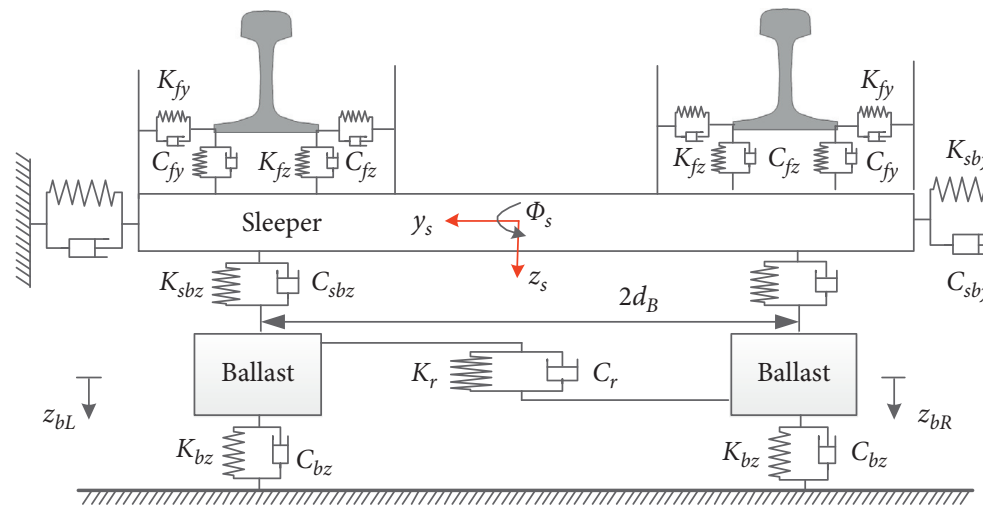

(b)

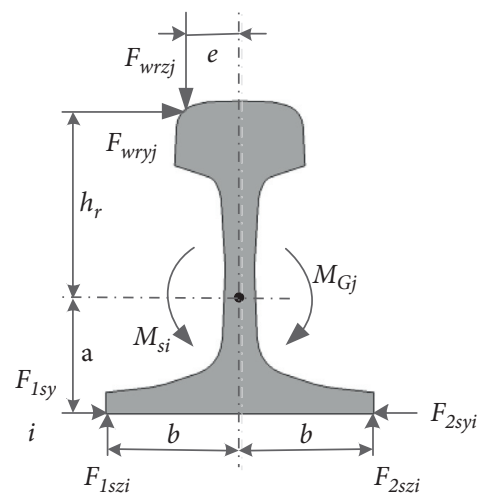

(c)

FIGURE 3: Schematic of ballasted track model: (a) main view and (b) side view.

$$
\left\{\begin{array}{l}
\rho A_{r} \frac{\partial^{2} y(x, t)}{\partial t^{2}}+\kappa_{y} G A_{r}\left[\frac{\partial \psi_{z}(x, t)}{\delta x}-\frac{\partial^{2} y(x, t)}{\partial x^{2}}\right]=-\sum_{i=1}^{N s} F_{s y i}(t) \delta\left(x-x_{s i}\right)+\sum_{j=1}^{N w} F_{w r y j}(t) \delta\left(x-x_{w j}\right) \\
\rho I_{z} \frac{\partial^{2} \psi_{z}(x, t)}{\partial t^{2}}+\kappa_{y} G A_{r}\left[\psi_{z}(x, t)-\frac{\partial y(x, t)}{\partial x}\right]-E I_{z} \frac{\partial^{2} \psi_{z}(x, t)}{\partial x^{2}}=0
\end{array}\right.
$$


where $I_{z}$ is the second moment of area of the rail cross section about the $z$-axis and $\kappa_{y}$ is the lateral shear coefficient, $\kappa_{y}=0.4507$.

The equation of motion describing the torsional deflection $\Psi_{x}$ of the rail subjected to the wheel/rail forces and support forces is formulated as

$$
\begin{aligned}
\rho I_{0} \frac{\partial^{2} \phi(x, t)}{\partial t^{2}}-G K \frac{\partial^{2} \phi(x, t)}{\partial t^{2}}= & -\sum_{i=1}^{N s} M_{s i}(t) \delta\left(x-x_{s i}\right) \\
& +\sum_{j=1}^{N w} M_{G j}(t) \delta\left(x-x_{w j}\right),
\end{aligned}
$$

where $I_{0}$ is the polar moment of inertia of the rail cross section and GK is the torsional stiffness coefficient.

The above governing partial differential equations (7) (9) describing the deflections of the rail can be converted to a series of ordinary differential equations using the variable separation method in terms of generalized coordinates as

$$
\begin{aligned}
z(x, t) & =\sum_{k=1}^{N_{z}} Z_{k}(x) q_{z k}(t), \\
\psi_{z}(x, t) & =\sum_{k=1}^{N_{y z}} \psi_{z k}(x) w_{z k}(t), \\
y(x, t) & =\sum_{k=1}^{N_{y}} Y_{k}(x) q_{y k}(t), \\
\psi_{y}(x, t) & =\sum_{k=1}^{N_{y y}} \psi_{y k}(x) w_{y k}(t), \\
\phi(x, t) & =\sum_{k=1}^{N_{\phi}} \phi_{k}(x) q_{T k}(t),
\end{aligned}
$$

where $q_{y k}(\mathrm{t}), q_{z k}(\mathrm{t}), q_{T k}(\mathrm{t}), w_{z k}(t)$, and $w_{y k}(t)$ are the vectors of corresponding modal coordinates, $N$ in the above formulation relates to the number of modes considered for each coordinate, and $Z_{k}(x), \Psi_{z k}(x), Y_{k}(x)$, $\Psi_{y k}(x)$, and $\Phi_{k}(x)$ are the normalized shape functions of the rail. Using the condition that the rail is simply supported at two ends, the normalized shape functions are given as

$$
\begin{aligned}
Z_{k}(x) & =\sqrt{\frac{2}{\rho I_{z} l}} \sin \left(\frac{k \pi}{l} x\right), \\
\psi_{z k}(x) & =\sqrt{\frac{2}{\rho I_{y} l}} \cos \left(\frac{k \pi}{l} x\right), \\
Y_{k}(x) & =\sqrt{\frac{2}{\rho I_{y} l}} \sin \left(\frac{k \pi}{l} x\right), \\
\psi_{y k}(x) & =\sqrt{\frac{2}{\rho I_{z} l}} \cos \left(\frac{k \pi}{l} x\right), \\
\phi_{k}(x) & =\sqrt{\frac{2}{\rho I_{0} l}} \sin \left(\frac{k \pi}{l} x\right) .
\end{aligned}
$$

Upon substituting the above relations in the governing equations of motion, equations (7) (9), and applying the normalized mode shape functions of the rails, the partial differential equations of the rail are converted to a set of ordinary differential equations, such that

$$
\begin{aligned}
& \left\{\begin{array}{l}
\ddot{g}_{z k}(t)+\frac{\kappa_{z} G A_{r}}{m}\left(\frac{k \pi}{l}\right)^{2} q_{z k}(t)-\kappa_{z} G A_{r} \frac{k \pi}{l} \sqrt{\frac{1}{m \rho I_{y}}} w_{y k}(t)=-\sum_{i=1}^{N s} F_{s z i}(t) Z_{k}\left(x_{s i}\right)+\sum_{j=1}^{N w} F_{w r z j}(t) Z_{k}\left(x_{w j}\right), \\
\ddot{w}_{y k}(t)+\left[\frac{\kappa_{z} G A_{r}}{\rho I_{y}}+\frac{E I_{y}}{\rho I_{y}}\left(\frac{k \pi}{l}\right)^{2}\right] w_{y k}(t)-\kappa_{z} G A_{r} \frac{k \pi}{l} \sqrt{\frac{1}{m \rho I_{y}}} q_{z k}(t)=0,
\end{array}\right. \\
& \left\{\begin{array}{l}
\ddot{g}_{y k}(t)+\frac{\kappa_{y} G A_{r}}{m}\left(\frac{k \pi}{l}\right)^{2} q_{y k}(t)-\kappa_{y} G A_{r} \frac{k \pi}{l} \sqrt{\frac{1}{m \rho I_{z}}} w_{z k}(t)=-\sum_{i=1}^{N s} F_{s y i}(t) Y_{k}\left(x_{s i}\right)+\sum_{j=1}^{N w} F_{w r y j}(t) Y_{k}\left(x_{w j}\right), \\
\ddot{w}_{z k}(t)+\left[\frac{\kappa_{y} G A_{r}}{\rho I_{z}}+\frac{E I_{z}}{\rho I_{z}}\left(\frac{k \pi}{l}\right)^{2}\right] w_{z k}(t)-\kappa_{y} G A_{r} \frac{k \pi}{l} \sqrt{\frac{1}{m \rho I_{z}}} q_{y k}(t)=0,
\end{array}\right. \\
& \ddot{g}_{T k}(t)+\frac{G K}{\rho I_{0}}\left(\frac{k \pi}{l}\right)^{2} q_{T k}(t)=-\sum_{i=1}^{N s} M_{s i}(t) \phi_{k}\left(x_{s i}\right)+\sum_{j=1}^{N w} M_{G j}(t) \phi_{k}\left(x_{w j}\right) .
\end{aligned}
$$


The solutions of equations (13) (15) yield deflection responses of the rail, which are applied to the vehicle model to determine the normal contact forces, $F_{w r z i}$ and $F_{w r y i}$ ( $i=1 \sim 4)$, using the Hertzian contact model available in the SIMPACK platform.

The high-magnitude impact forces induced by the wheel defects are transmitted to the ballast through the fasteners, which causes vibration of the ballast. Meanwhile, the vibration of the ballast directly contributes to the rail deflections and thus the wheel/rail contact forces. As Figure 3 shows, the fastening is treated as the spring-damper element with vertical stiffness $K_{f z}$, vertical damping coefficient $C_{f z}$, lateral stiffness $K_{f y}$, and lateral damping coefficient $C_{f z}$. The sleeper is modeled as a rigid body with mass $m_{s}$ and inertial moment $I_{s x}$. The motions of the sleeper are described by vertical displacement $z_{s}$ and lateral displacement $y_{s}$ of the mass center of the sleeper and rotation angle $\Phi_{s}$. The ballast is modeled as the equivalent mass block with mass $m_{b}$ and only the vertical motion $z_{b L}\left(z_{b R}\right)$ is considered. Besides, the equivalent shear spring-damping elements $K_{r}-C_{r}$ are set between track bed blocks to consider the shear interaction between left and right, front, and rear adjacent track beds. Parameters of ballasted track model are listed in Table 1.

2.3. Vehicle Model. The mathematical model coupling the lateral and vertical motions is considered in order to accurately simulate the operation performance of the Chinese open top wagon $\mathrm{C} 80$. The model consists of a rigid car body supported on two rigid bolsters via the center plates and side bearings, and four flexible wheelsets coupled to four side frames through the primary rubber suspensions. Meanwhile, two side frames and one bolster are connected by coil springs and friction wedge dampers. Each wheelset is considered as a rotating flexible body, whose deflection responses are obtained from modal superposition, shown in Section 2.1.

The freight wagon has friction elements such as center plate and side bearing, which will provide rotary friction torques between car body and bogies to ensure the vehicle hunting stability. The rotary friction torque of the center plate can be calculated by the following:

$$
\begin{aligned}
T_{c} & =\int_{0}^{R_{c}} 2 \pi r^{2} \mu_{c} \frac{P_{c}}{A_{c}} \mathrm{~d} r, \\
& =\frac{2}{3} \mu_{c} P_{c} R_{c},
\end{aligned}
$$

where $P_{c}$ is the load on the center plate, $A_{c}$ and $R_{c}$ are the area and radius of the center plate, and $\mu_{c}$ is the friction coefficient of the center plate surface. The side bearing here is a double acting elastic side bearing, which can effectively prevent the excessive increase of the rotary friction torque as the gap reached and improve the curving performance of the freight wagon. The rotary friction torque of the side bearing can be calculated as follows:

$$
T_{s}= \begin{cases}\left(P_{s}+k_{z} \Delta z\right) \mu_{s} d_{s}, & \Delta z \leq \Delta c \\ \left(P_{s}+k_{z} \Delta c\right) \mu_{s} d_{s}, & \Delta z>\Delta c\end{cases}
$$

where $P_{s}$ is side bearing preload, $k_{z}$ is the vertical stiffness of the side bearing, $\Delta c$ is side bearing gap with $\Delta c=6 \mathrm{~mm}, \mu_{s}$ is the friction coefficient of the side bearing surface, and $d_{s}$ is the distance between the side bearing and the bogie center. In addition, the Chinese type LM wheel profile and CHN60 rail profile are adopted for the simulation. The structural and suspension parameters of freight wagon model are set according to Table 2 .

2.4. Wheel Polygonalisation. Wheel polygonalisation is described by variations in the wheel radius as a function of angular position of the wheel $\phi_{h}$. Figure 4(a) illustrates the OOR deformities measured on a wheel, which suggests nearly periodic variations or wheel polygonalisation. The measured wear profile is idealised by a periodic waveform superimposed on the wheel circumference, as seen in Figure 4(b). The coordinates of a point on the circumference or the contact point can thus be expressed as

$$
\left\{\begin{array}{l}
x=\left(R_{w}+A_{p} \sin N_{p} \phi_{h}\right) \sin \phi_{h}, \\
y=\left(R_{w}+A_{p} \sin N_{p} \phi_{h}\right) \cos \phi_{h},
\end{array} \phi_{h} \in[0,2 \pi],\right.
$$

where $x$ and $y$ are the coordinates of a point on the wheel circumference, $A_{p}$ denotes the amplitude of the polygonal wear, $N_{p}$ is the order of harmonic of the polygonal wear, and $R_{w}$ is the nominal wheel radius. The radius of the wheel at a given point on the wheel circumference can be given by $R_{p}=R_{w}+A_{p} \sin N_{p} \Phi_{h}$.

Through measurements of circumferential profiles of 99 different wheels employed in high-speed freight and commuter trains, Johansson found that the order of polygonalisation in freight wagon is mostly below 10 [21], and the similar phenomenon is also reported in reference [22]. Therefore, low-order wheel polygonalisation is simulated to establish the mapping relationship between wheel/rail force and wheel polygonalisation in this paper.

2.5. Model Validation. The wheel polygonal wear induced wheel/rail contact forces have been widely investigated experimentally and analytically. Most of these studies, however, focus on single order polygonalisation. The validity of the coupled vehicle-track dynamic model in the presence of wheel polygonal wear is thus examined by comparing the simulation results with the reported measured data [5]. The simulation results are obtained for the vehicle-track model considering the reported experimental conditions $0.125 \mathrm{~m}$ amplitude of $10^{\text {th }}$-order polygonalisation, while the wheel polygonal wear is limited to the leading wheelset. Simulation results in terms of peak wheel/rail contact force deviations from the static load are compared with the reported measured data in the $0-100 \mathrm{~km} / \mathrm{h}$ speed range in Figure 5. The comparisons suggest reasonably good agreements with the experimental results in saturation force and variation tendency. Both the simulation and experimental results show saturation of the peak force in the $50-60 \mathrm{~km} / \mathrm{h}$ speed range. However, the saturation forces appear at different speeds, which is caused by the structure of the track. 
TABle 1: Parameters of the ballasted track.

\begin{tabular}{|c|c|c|}
\hline Variable & Notation & Value \\
\hline$E$ & Young's modulus of rail & $2.06 \times 10^{11} \mathrm{~N} / \mathrm{m}^{2}$ \\
\hline G & Shear modulus of rail & $7.92 \times 10^{10} \mathrm{~N} / \mathrm{m}^{2}$ \\
\hline$\rho$ & Density of rail & $7850 \mathrm{~kg} / \mathrm{m}^{2}$ \\
\hline$A$ & Cross-section area of rail & $7.745 \times 10^{-3} \mathrm{~m}^{2}$ \\
\hline$I_{y}$ & Second moments of area of rail cross section about the $y$-axis & $5.240 \times 10^{-6} \mathrm{~m}^{2}$ \\
\hline$I_{z}$ & Second moments of area of rail cross section about the $z$-axis & $3.217 \times 10^{-5} \mathrm{~m}^{4}$ \\
\hline$I_{0}$ & Solar moment of inertia of rail cross section & $3.741 \times 10^{-5} \mathrm{~m}^{4}$ \\
\hline$e$ & Distance from load point to the central line of rail cross section & $0.023 \mathrm{~m}$ \\
\hline$a$ & Distance from bottle surface to the torsional center of rail cross section & $0.08147 \mathrm{~m}$ \\
\hline$b$ & Distance from bottle surface left/right side to the central line of rail cross section & $0.075 \mathrm{~m}$ \\
\hline$h_{R}$ & Distance from top surface to the torsional center of rail cross section & $0.095 \mathrm{~m}$ \\
\hline$K_{f z}$ & Equivalent vertical stiffness of fastening & $2.8 \times 10^{7} \mathrm{~N} / \mathrm{m}$ \\
\hline$K_{f y}$ & Equivalent lateral stiffness of fastening & $3.0 \times 10^{7} \mathrm{~N} / \mathrm{m}$ \\
\hline$C_{f z}$ & Equivalent vertical damping coefficient of fastening & $3.625 \times 10^{4} \mathrm{~N} / \mathrm{m}$ \\
\hline$C_{f y}$ & Equivalent lateral damping coefficient of fastening & $3.0 \times 10^{4} \mathrm{~N} / \mathrm{m}$ \\
\hline$m_{s}$ & Mass of sleeper & $349 \mathrm{~kg}$ \\
\hline$I_{s x}$ & Moment of inertia of sleeper about the $x$-axis & $199 \mathrm{~kg} \mathrm{~m}^{2}$ \\
\hline$m_{b}$ & Mass of ballast equivalent mass block & $139.8 \mathrm{~kg}$ \\
\hline$K_{f z}$ & Equivalent vertical stiffness of fastening & $2.8 \times 10^{7} \mathrm{~N} / \mathrm{m}$ \\
\hline$K_{f y}$ & Equivalent lateral stiffness of fastening & $3.0 \times 10^{7} \mathrm{~N} / \mathrm{m}$ \\
\hline$C_{f z}$ & Equivalent vertical damping coefficient of fastening & $3.6 \times 10^{4} \mathrm{~N} \cdot \mathrm{s} / \mathrm{m}$ \\
\hline$C_{f y}$ & Equivalent lateral damping coefficient of fastening & $3.0 \times 10^{4} \mathrm{~N} \cdot \mathrm{s} / \mathrm{m}$ \\
\hline$K_{s b y}$ & Lateral equivalent stiffness between sleeper and ballast & $7.0 \times 10^{7} \mathrm{~N} / \mathrm{m}$ \\
\hline$C_{\text {sby }}$ & Lateral equivalent damping coefficient between sleeper and ballast & $6.0 \times 10^{4} \mathrm{~N} \cdot \mathrm{s} / \mathrm{m}$ \\
\hline$K_{s b z}$ & Vertical equivalent stiffness between sleeper and ballast & $7.0 \times 10^{7} \mathrm{~N} / \mathrm{m}$ \\
\hline$C_{s b z}$ & Vertical equivalent damping coefficient between sleeper and ballast & $6.0 \times 10^{4} \mathrm{~N} \cdot \mathrm{s} / \mathrm{m}$ \\
\hline$K_{b z}$ & Vertical equivalent stiffness between ballast and ground & $6.7 \times 10^{7} \mathrm{~N} / \mathrm{m}$ \\
\hline$K_{b z}$ & Vertical equivalent damping coefficient between ballast and ground & $3.1 \times 10^{4} \mathrm{~N} \cdot \mathrm{s} / \mathrm{m}$ \\
\hline$K_{r}$ & Vertical equivalent stiffness between ballasts & $7.8 \times 10^{7} \mathrm{~N} / \mathrm{m}$ \\
\hline$C_{r}$ & Vertical equivalent damping coefficient between ballasts & $8.0 \times 10^{4} \mathrm{~N} \cdot \mathrm{s} / \mathrm{m}$ \\
\hline$d_{B}$ & Distance between mass centers of ballast and sleeper & $0.6 \mathrm{~m}$ \\
\hline
\end{tabular}

TABLe 2: Freight wagon model parameters.

\begin{tabular}{lc}
\hline Parameters & Values \\
\hline Car body mass & $10829 \mathrm{~kg}$ \\
Side frame mass & $497 \mathrm{~kg}$ \\
Bolster mass & $145 \mathrm{~kg}$ \\
Wheelset mass & $1171 \mathrm{~kg}$ \\
Car body roll moment of inertia around $x$-axis & $6.932 \times 10^{4} \mathrm{~kg} \cdot \mathrm{m}^{2}$ \\
Car body pitch moment of inertia around $y$-axis & $1.837 \times 10^{5} \mathrm{~kg} \cdot \mathrm{m}^{2}$ \\
Car body yaw moment of inertia around $z$-axis & $2.127 \times 10^{5} \mathrm{~kg} \cdot \mathrm{m}^{2}$ \\
Side frame roll moment of inertia around $x$-axis & $20.735 \mathrm{~kg} \cdot \mathrm{m}^{2}$ \\
Side frame pitch moment of inertia around $y$-axis & $188.2 \mathrm{~kg} \cdot \mathrm{m}^{2}$ \\
Side frame yaw moment of inertia around $z$-axis & $172.5 \mathrm{~kg} \cdot \mathrm{m}^{2}$ \\
Bolster roll moment of inertia around $x$-axis & $259.7 \mathrm{~kg} \cdot \mathrm{m}^{2}$ \\
Bolster pitch moment of inertia around $y$-axis & $16.158 \mathrm{~kg} \cdot \mathrm{m}^{2}$ \\
Bolster yaw moment of inertia around $z$-axis & $258.08 \mathrm{~kg} \cdot \mathrm{m}^{2}$ \\
Wheelset roll moment of inertia around $x$-axis & $700 \mathrm{~kg} \cdot \mathrm{m}^{2}$ \\
Wheelset pitch moment of inertia around $y$-axis & $72 \mathrm{~kg} \cdot \mathrm{m}^{2}$ \\
Wheelset yaw moment of inertia around $z$-axis & $700 \mathrm{~kg} \cdot \mathrm{m}^{2}$ \\
Primary suspension vertical stiffness along $z$-axis & $160 \mathrm{MN} / \mathrm{m}^{2}$ \\
Secondary suspension vertical stiffness along $z$-axis & $2.233 \mathrm{MN} / \mathrm{m}$ \\
The distance between the side bearing and the bogie center & $0.76 \mathrm{~m}$ \\
Radius of friction moment of center plate & $0.125 \mathrm{~m}$ \\
Side bearing preload & $19.8 \mathrm{kN}$ \\
\hline
\end{tabular}




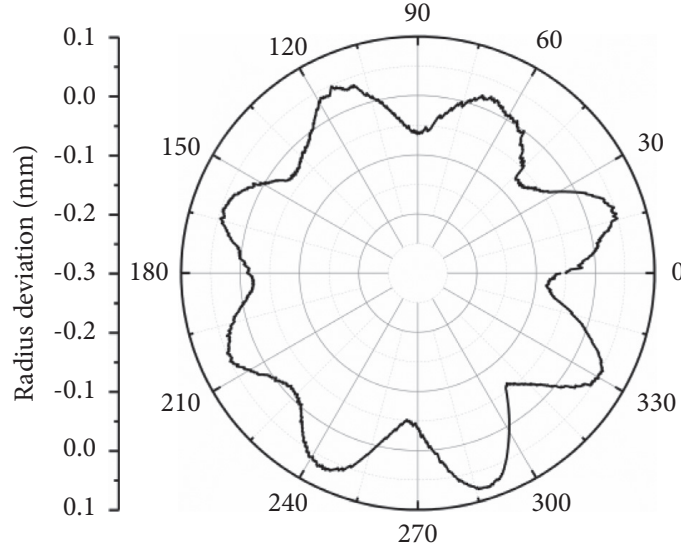

(a)

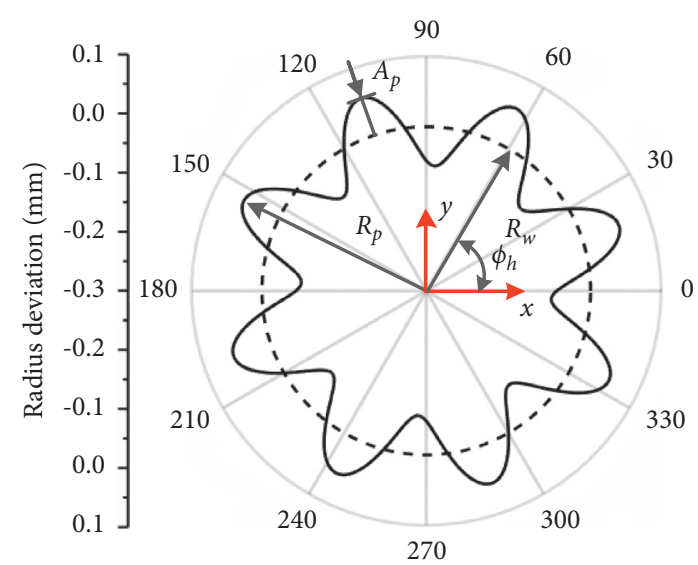

(b)

Figure 4: (a) Measured circumferential polygonal wear and (b) polygonal wear idealised by a harmonic waveform.

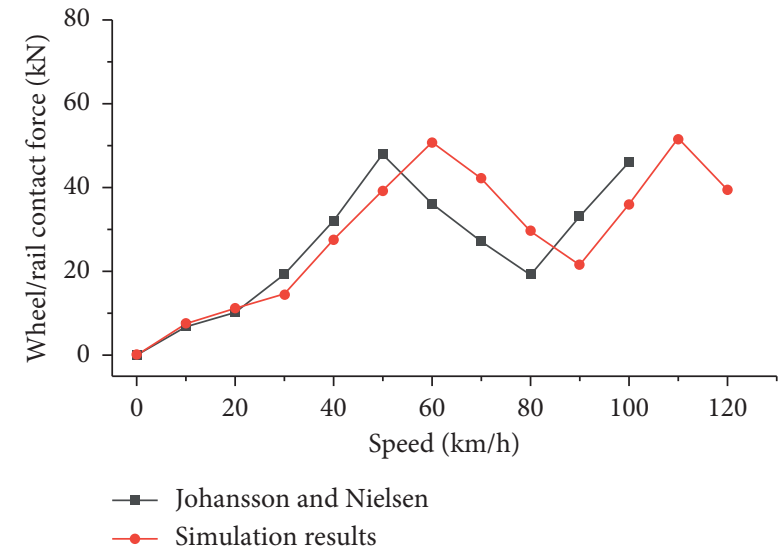

FIGURE 5: Comparisons of the peak wheel/rail contact force deviations from the static load with vehicle speed obtained from coupled vehicle-track model with the reported measured data [5].

\section{Results and Discussions}

In this study, the measured polygonal wear is idealised by a harmonic variation in the wheel radius, as described in section 2.4. The vehicle-track model simulations are subsequently performed to evaluate the dynamic responses of the vehicle system under excitations caused by polygonal wear. The simulation results in each case are obtained under excitations due to polygonal wear of both the left and right wheels of the leading wheelset of the front bogie, while assuming negligible phase difference between the two wheels' deformities.

3.1. Influences of Vehicle Speed and Wear Amplitude. Figure 6 illustrates the effect of forward speed on the resulting maximum and minimum wheel/rail contact force magnitudes, both empty and loaded vehicles, considering from $0.05 \mathrm{~mm}$ to $0.3 \mathrm{~mm}$ amplitude 6th-order polygonal wear on both the wheels of the leading wheelset. Take polygonal wear with amplitude of $0.1 \mathrm{~mm}$ as an example; the maximum contact forces of empty vehicle increase with vehicle speed in the $20-90 \mathrm{~km} / \mathrm{h}$ speed range and decrease at speeds exceeding $90 \mathrm{~km} / \mathrm{h}$ while the maximum contact forces of loaded vehicle reach saturation at speed of $100 \mathrm{~km} / \mathrm{h}$. Corresponding to maximum of wheel/rail contact force, the minimum of wheel/rail contact force of loaded vehicles and the maximum wheel-rail force are approximately symmetrical with the static load. Meanwhile, the minimum of wheel/rail contact force of empty vehicle decreases with the speed until reducing to 0 at $90 \mathrm{~km} / \mathrm{h}$, which indicates wheel/rail separation.

Apart from the forward speed, the magnitude of the wheel/rail contact force is strongly dependent on the amplitude of the polygonal wear. Figure 7 illustrates the effect of wear amplitude on maxima and minima of the wheel/rail contact force of empty and loaded vehicles, respectively, caused by the 6th-order polygonal wear at speed of $90 \mathrm{~km} / \mathrm{h}$ and $100 \mathrm{~km} / \mathrm{h}$. The results of empty clearly show a nearly linear increase and decrease in maximum and minimum contact force, respectively, with increasing wear amplitude at the speed of $90 \mathrm{~km} / \mathrm{h}$. Different from the variation at speed of $90 \mathrm{~km} / \mathrm{h}$, there is a rapid increase in the maximum contact force while there is a decrease to 0 in the minimum between $0.05 \mathrm{~mm}$ amplitude and $0.1 \mathrm{~mm}$ amplitude, that the wheel/ rail separation contributes to a rapid increase in the maximum contact force. It is necessary to limit the polygonal wear amplitude preventing the separation of wheel and rail. The phenomenon in Figure 7(b) revealed by maximum and minimum contact force is similar to that in Figure 7 (a) except for polygonal wear amplitude, which is caused by the different axel load between them.

Figures 8(a) and 8(b) illustrate the frequency spectra of wheel/rail contact force deviations from the static load of empty vehicle induced by $0.1 \mathrm{~mm}$ amplitude and $0.2 \mathrm{~mm}$ amplitude, respectively, of 6th-order polygonal wear in the $20-120 \mathrm{~km} / \mathrm{h}$ speed range. The results suggest that the passing frequency of wheel polygonalisation $\left(f_{\text {oor }}\right)$ increases with the vehicle speed and variation tendency of force peaks along the passing frequency is the same as that of maximum wheel/rail contact force in Figure 6(a), which reveals that 


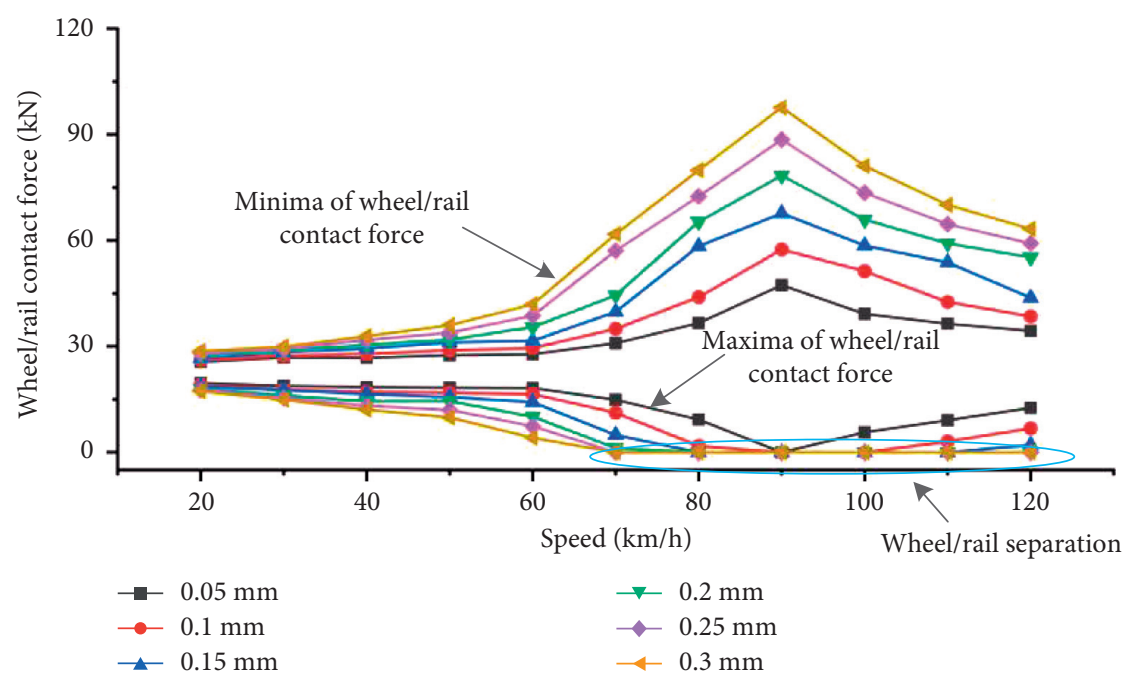

(a)

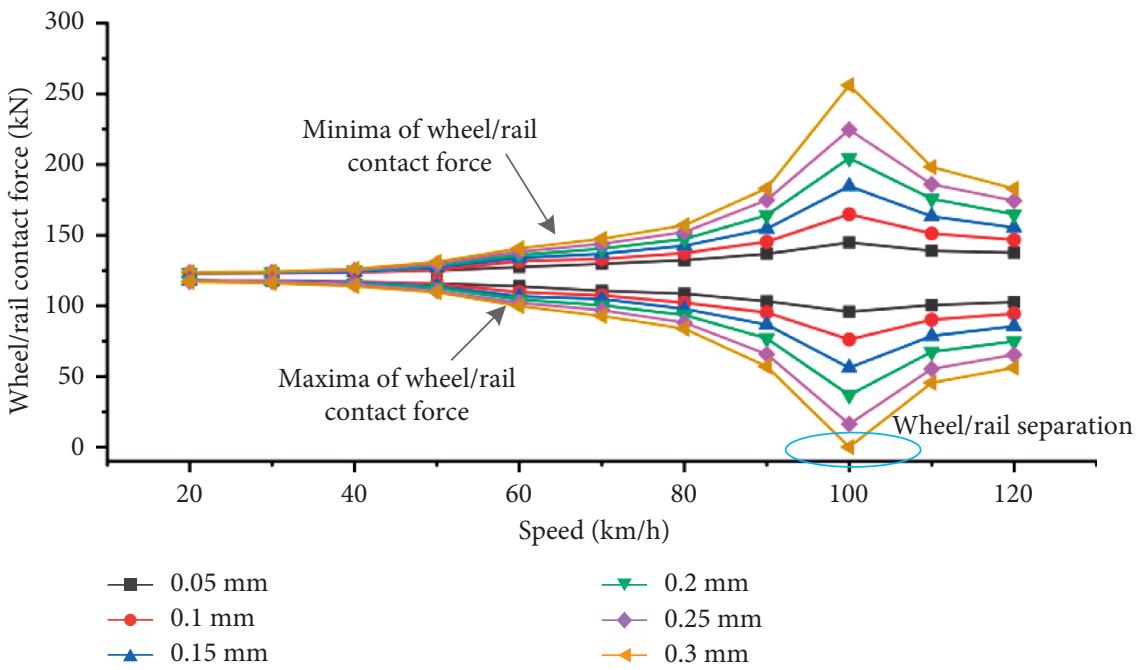

(b)

FIGURE 6: Influence of vehicle speed on the maximum and minimum wheel/rail contact force under the 6th-order polygonal wear: (a) empty vehicle and (b) loaded vehicle.

additional wheel/rail contact force is induced by polygonal wear. Besides, the spectra also revealed force peaks corresponding to multiples of $f_{\text {oor }}$, namely, $2 f_{\text {oor }}$ and $3 f_{\text {oor }}$, appearing the same as that of the minimum of wheel/rail force reduced to 0 in Figure 6(a). These are likely due to wheel/rail separation induced elastic deformations of the wheelset at some speeds. Figures 8(c) and 8(d) illustrate the frequency spectra of wheel/rail contact force of loaded vehicle with $0.1 \mathrm{~mm}$ amplitude and $0.2 \mathrm{~mm}$ amplitude, respectively, of 6th-order polygonal wear in the $20-120 \mathrm{~km} / \mathrm{h}$ speed range. Unlike empty vehicles, there are no corresponding to multiples of $f_{\text {oor }}$, which is due to no wheel-rail separation shown in Figure 6(b).

3.2. Influence of Order of Polygonal Wear. Figure 9 illustrates the influence of order of polygonal wear on the maxima of the wheel/rail contact force deviations from the static load for $0.1 \mathrm{~mm}$ wear amplitude in the $60-130 \mathrm{~km} / \mathrm{h}$ speed range. The results reveal that $1^{\text {st }}$-order and $3^{\text {rd }}$-order wheel polygonalisation, whether empty or loaded vehicles, have limited influence on wheel/rail contact forces. Furthermore, the maxima contact forces for empty vehicles induced by $5^{\text {th }}$ order, $7^{\text {th }}$-order, and $9^{\text {th }}$-order polygons are saturated at $110 \mathrm{~km} / \mathrm{h}, 80 \mathrm{~km} / \mathrm{h}$, and $60 \mathrm{~km} / \mathrm{h}$, respectively. By contrast, the saturation forces induced by wheel polygonalisation appear at $115 \mathrm{~km} / \mathrm{h}, 85 \mathrm{~km} / \mathrm{h}$, and $65 \mathrm{~km} / \mathrm{h}$. This is likely caused by the wheel/rail coupled vertical vibration mode near $60 \mathrm{~Hz}$, as reported in [23, 24]. This relatively low-frequency mode is also referred to as "P2 force" or "P2 resonance" [25] and is related to effective masses of the wheelset and the rail, which cause the different passing frequency between empty and loaded vehicles, and stiffness of the primary suspension and the rail supports. Meanwhile, the passing frequency induced by polygonal wear resonates with $\mathrm{P} 2$, which intensifies the wheel/rail contact force resulting in 


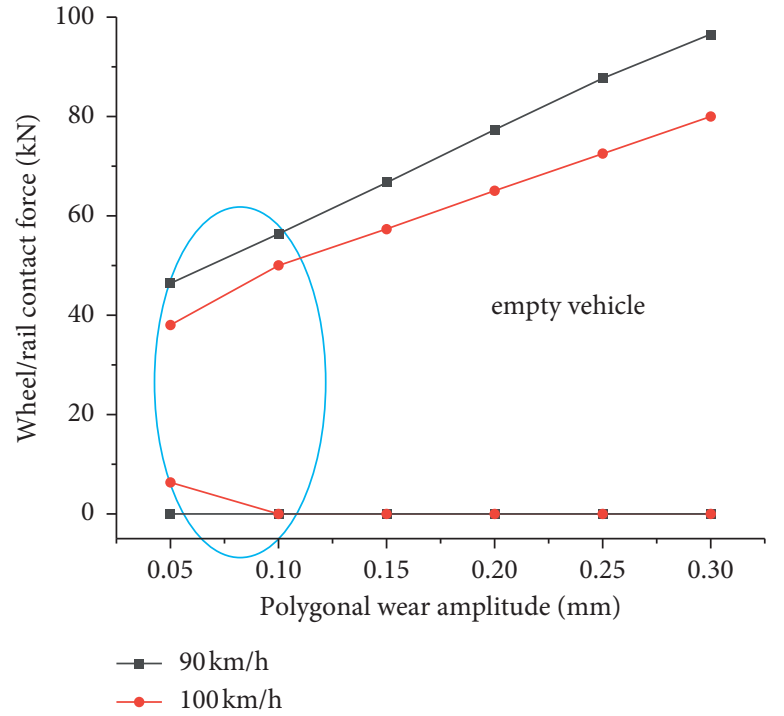

(a)

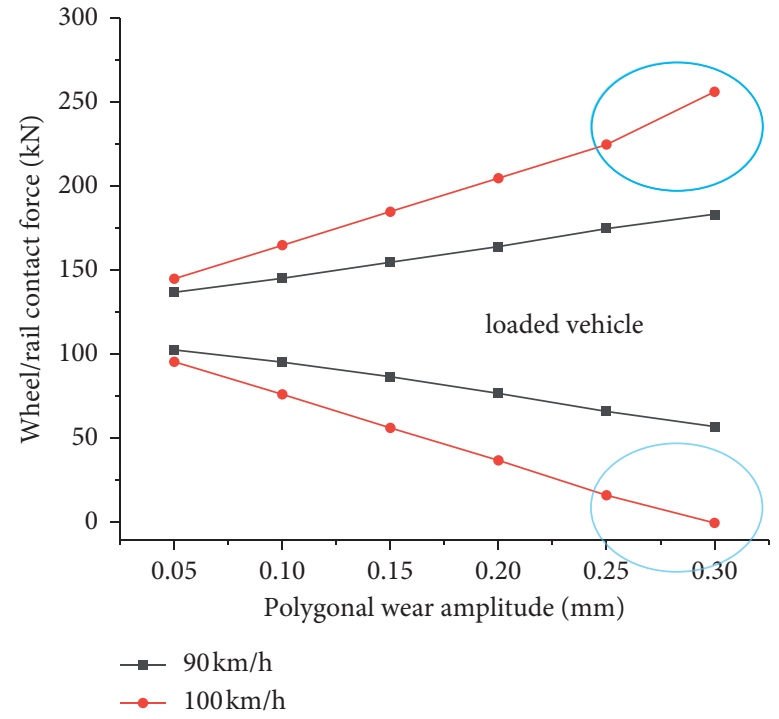

(b)

FIGURE 7: Influence of polygonal wear amplitude on the maxima and minima of the wheel/rail contact forces: (a) empty vehicle and (b) loaded vehicle.

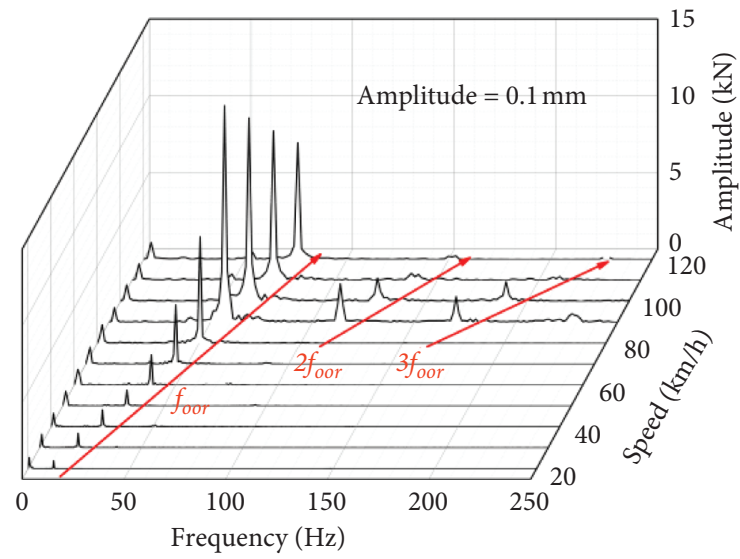

(a)

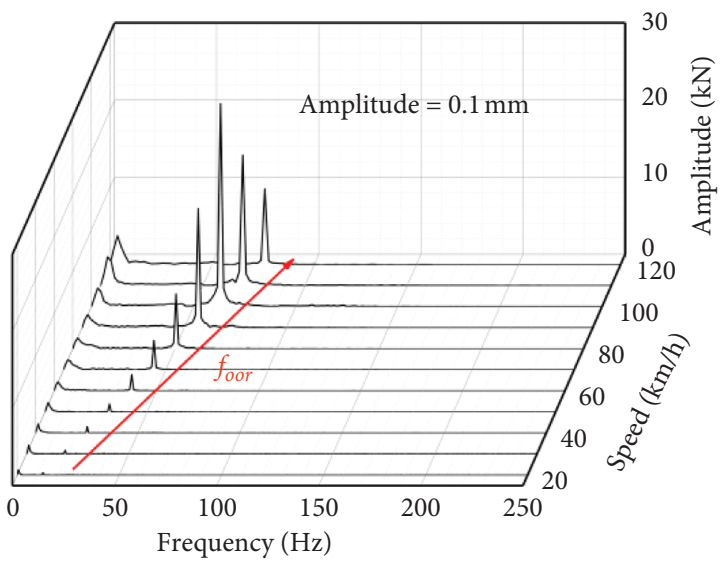

(c)

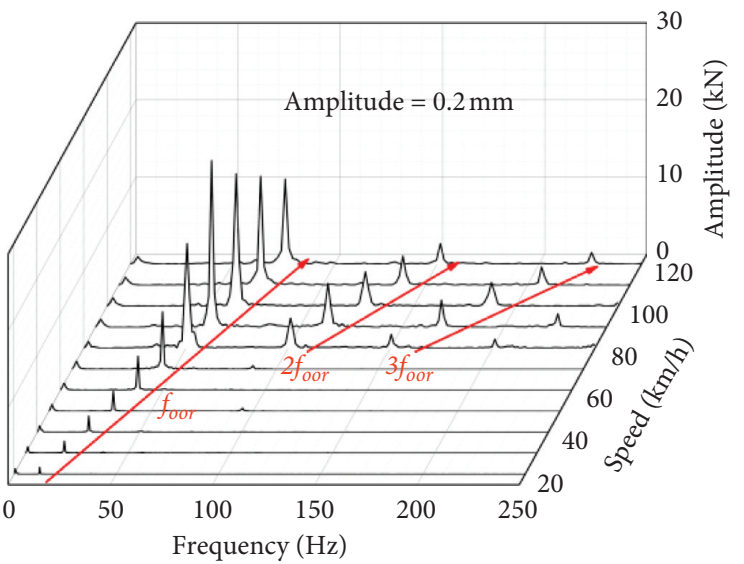

(b)

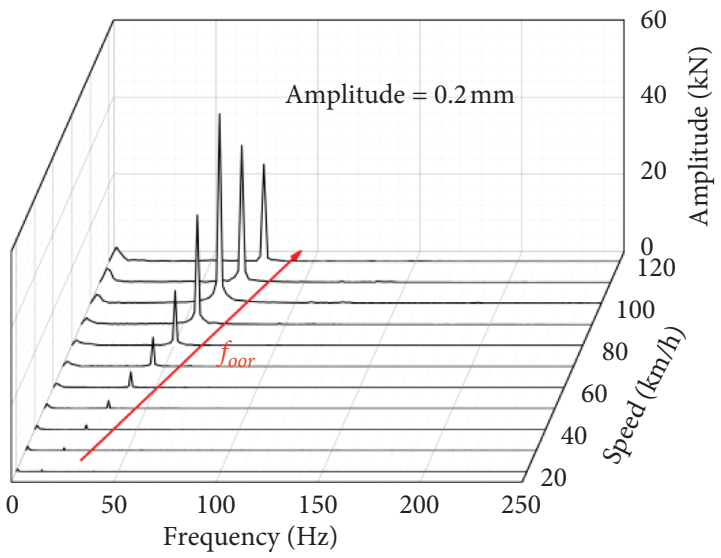

(d)

Figure 8: Frequency spectra of wheel/rail contact force in the $20-120 \mathrm{~km} / \mathrm{h}$ speed range: (a) empty vehicle (amplitude $=0.1 \mathrm{~mm}$ ), (b) empty vehicle (amplitude $=0.2 \mathrm{~mm})$, (c) loaded vehicle $($ amplitude $=0.1 \mathrm{~mm})$, (d) loaded vehicle $($ amplitude $=0.2 \mathrm{~mm})$. 


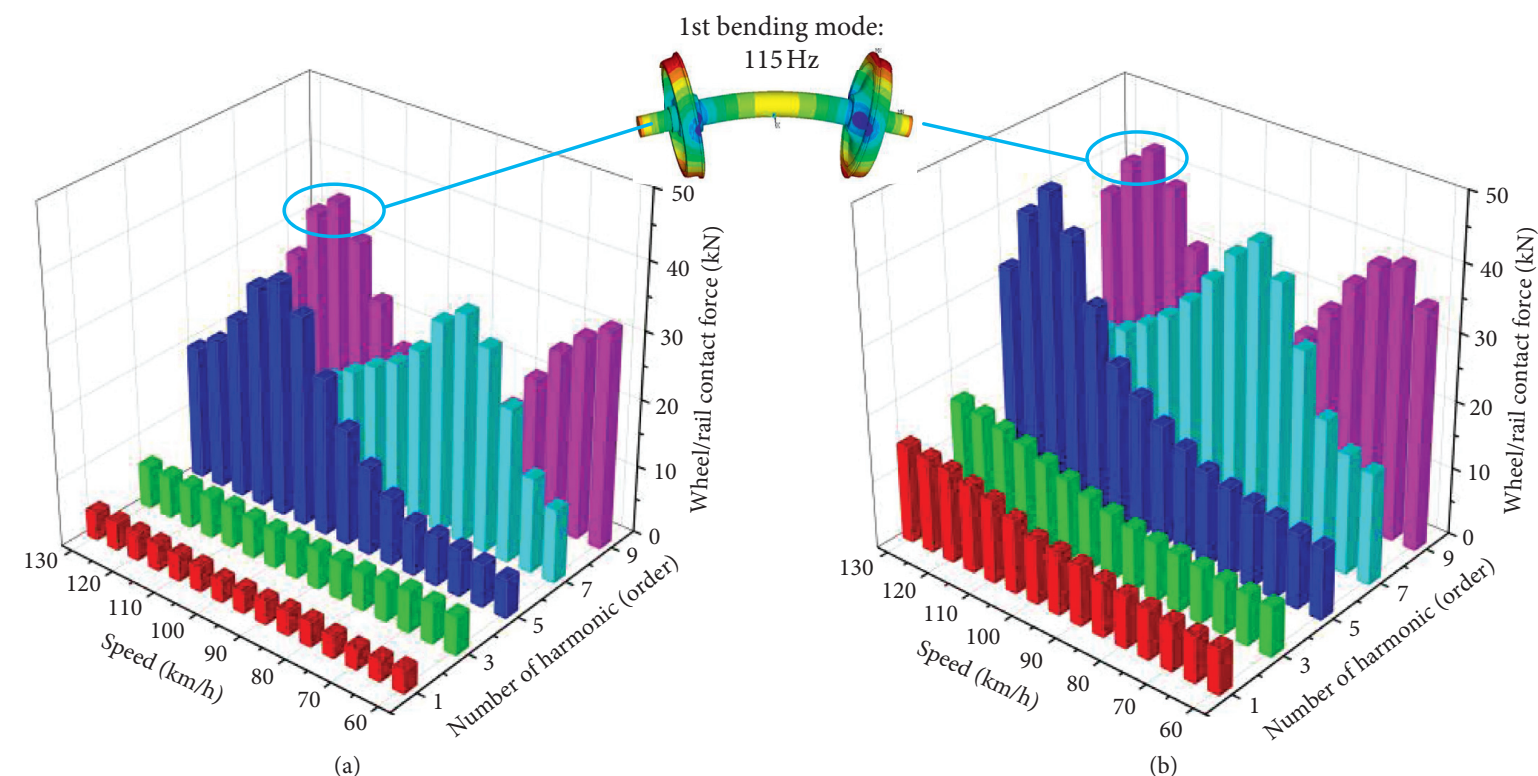

Figure 9: Effect of order of polygonal wear on maxima of the wheel $/$ rail contact force deviations from the static load in the $60-120 \mathrm{~km} / \mathrm{h}$ speed range: (a) empty vehicle and (b) loaded vehicle (amplitude $=0.1 \mathrm{~mm}$ ).

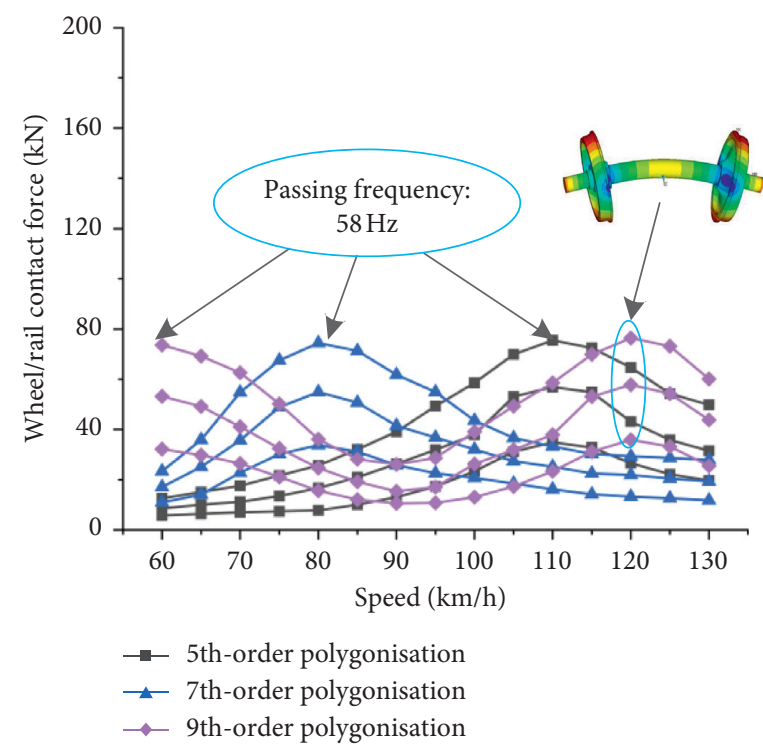

(a)

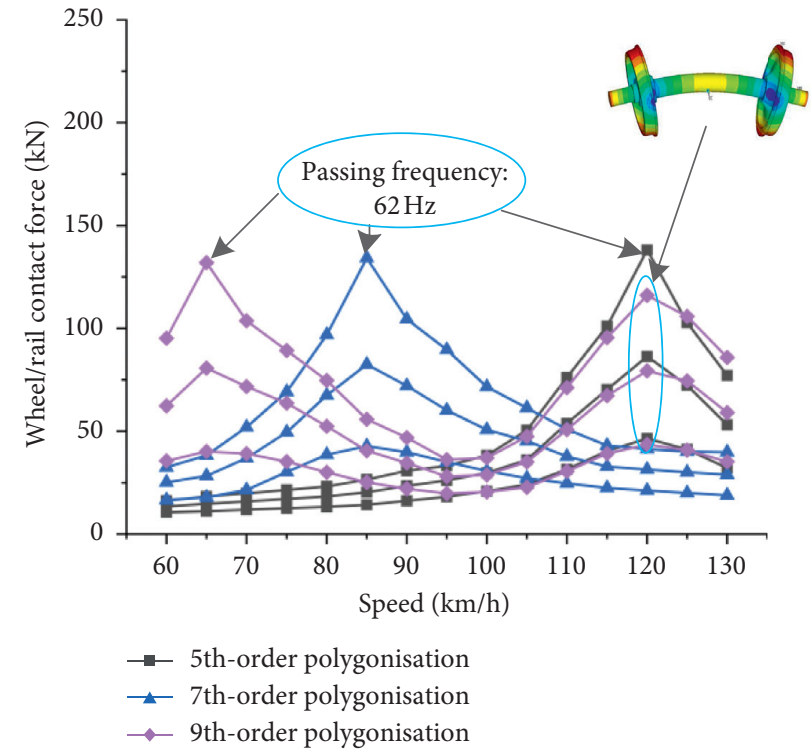

(b)

FIGURE 10: Mapping relation between the wheel/rail contact force deviations from the static load and polygonal wear order with difference amplitude.

the increase of polygon wear exponentially with time. Additionally, another peak value $(113 \mathrm{~Hz})$ induced by 9 th-order polygons, whether empty or loaded vehicles, appears near $120 \mathrm{~km} / \mathrm{h}$, which is close to the $1^{\text {st }}$-bending mode $(115 \mathrm{~Hz})$ of the wheelset as Figure 2 shows.

3.3. Mapping Relation. As the limited influence is made by $1^{\text {st }}$-order and $3^{\text {rd }}$-order wheel polygonalisation, only the mapping relations between induced wheel/rail force and $5^{\text {th }}$ order, $7^{\text {th }}$-order, and $9^{\text {th }}$-order polygonalisation are established in this section. Figure 10 illustrates the mapping relations between wheel/rail forces induced by the polygonalisation with $0.1 \mathrm{~mm}, 0.2 \mathrm{~mm}$, and $0.3 \mathrm{~mm}$ amplitude. The results reveal that amplitude variation of the polygonalisation only affects the amplitude of the saturation force, and the saturation forces of empty and loaded vehicles still appear when the passing frequency is $58 \mathrm{~Hz}$ and $113 \mathrm{~Hz}$, $62 \mathrm{~Hz}$, and $113 \mathrm{~Hz}$, respectively, which is primarily affected by $\mathrm{P} 2$ force and $1^{\text {st }}$-bend mode of wheelset. Besides, the difference between saturated wheel/rail forces induced by different polygonal order with the same amplitude is little 
and the induced wheel/rail forces are almost proportional to the polygonal amplitude, except when the wheel-rail separation occurs.

The passing frequency induced by polygonal wear resonates with P2 force, which intensifies the wheel/rail contact force resulting in the increase of polygon wear exponentially with time. When the wheel operation time is over a specified maintenance period, polygonal wear develops quickly.

Thus, it is very necessary to establish the mapping relationship between wheel/rail force and wheel polygonalisation to detect the state of passing vehicle wheelset by trackside detection, so as to find out and repair in time.

\section{Conclusion}

A comprehensive coupled vehicle-track dynamic model of open top wagon C80 is established so as to investigate the effects of low-order wheel polygonalisation on wheel/rail contact force. The model integrates flexible ballasted track and wheelset subsystem models so as to account for elastic deformations that may occur in the presence of repetitive impact loads induced by the wheel polygonalisation. The effects of amplitude and harmonic order of wheel polygonal wear, whether empty and loaded vehicles, are subsequently investigated and the corresponding mapping relations are obtained to detect polygonal wheel by trackside detection. Then, the conclusions can be drawn as follows:

(1) The induced wheel/rail force is almost proportional to the polygon amplitude, except increasing rapidly when the wheel/rail separation occurs

(2) $1^{\text {st }}$-order and $3^{\text {rd }}$-order polygons, whether empty vehicle and loaded vehicle, have limited influence on wheel/rail contact forces in the $20-130 \mathrm{~km} / \mathrm{h}$ speed range

(3) The saturation forces of empty and loaded vehicle appear when the passing frequency is $58 \mathrm{~Hz}$ and $113 \mathrm{~Hz}$ and $62 \mathrm{~Hz}$ and $113 \mathrm{~Hz}$, respectively, which is primarily affected by $\mathrm{P} 2$ force and 1st-bend mode of wheelset

\section{Data Availability}

The validity of the coupled vehicle-track dynamic model in the presence of wheel polygonal wear is thus examined by comparing the simulation results with the reported measured data in [5].

\section{Conflicts of Interest}

The authors declare that they have no conflicts of interest.

\section{Acknowledgments}

This work was supported by the National Natural Science Foundation of China (Grant numbers: U2034210 and 52102441) and Independent Research and Development Project of the State Key Laboratory of Traction Power (Grant number: 2019TPL-T18).

\section{References}

[1] X.-s. Jin, "Key problems faced in high-speed train operation," Journal of Zhejiang University Science A, vol. 15, no. 12, pp. 936-945, 2014.

[2] B. Peng, S. Iwnicki, P. Shackleton, and Y. Song, "General conditions for railway wheel polygonal wear to evolve," $\mathrm{Ve}$ hicle System Dynamics, vol. 59, no. 4, pp. 568-587, 2021.

[3] Y. Wu, X. Du, H. J. Zhang, Z. F. Wen, and X.-S. Jin, "Experimental analysis of the mechanism of high-order polygonal wear of wheels of a high-speed train," Journal of Zhejiang University - Science, vol. 18, no. 8, pp. 579-592, 2017.

[4] J. C. O. Nielsen and A. Johansson, "Out-of-round railway wheels-a literature survey," Proceedings of the Institution of Mechanical Engineers - Part F: Journal of Rail and Rapid Transit, vol. 214, no. 2, pp. 79-91, 2000.

[5] A. Johansson and J. C. O. Nielsen, "Out-of-round railway wheels-wheel-rail contact forces and track response derived from field tests and numerical simulations," Proceedings of the Institution of Mechanical Engineers - Part F: Journal of Rail and Rapid Transit, vol. 217, no. 2, pp. 135-146, 2003.

[6] D. W. Barke and W. K. Chiu, "A review of the effects of outof-round wheels on track and vehicle components," Proceedings of the Institution of Mechanical Engineers - Part F: Journal of Rail and Rapid Transit, vol. 219, no. 3, pp. 151-175, 2005.

[7] X. Y. Liu and W. M. Zhai, "Analysis of vertical dynamic wheel/rail interaction caused by polygonal wheels on highspeed trains," Wear, vol. 314, no. 2, pp. 282-290, 2014.

[8] X. W. Wu, S. Rakheja, and A. K. W. Ahmed, "Influence of a flexible wheelset on the dynamic responses of a high-speed railway car due to a wheel flat," Proceedings of the Institution of Mechanical Engineers - Part F: Journal of Rail and Rapid Transit, vol. 232, no. 4, pp. 1033-1048, 2018.

[9] X. S. Jin, L. Wu, J. Y. Fang, S. Q. Zhong, and L. Ling, “An investigation into the mechanism of the polygonal wear of metro train wheels and its effect on the dynamic behaviour of a wheel/rail system," Vehicle System Dynamics, vol. 50, no. 12, pp. 1817-1834, 2012.

[10] G. Q. Tao, Z. F. Wen, X. R. Liang, D. Ren, and X. Jin, “An investigation into the mechanism of the out-of-round wheels of metro train and its mitigation measures," Vehicle System Dynamics, vol. 57, no. 1, pp. 1-16, 2019.

[11] X. W. Wu, S. Rakheja, S. Qu, P. wu, J. Zeng, and A. K. W. Ahmed, "Dynamic responses of a high-speed railway car due to wheel polygonalisation," Vehicle System Dynamics, vol. 56, no. 12, pp. 1817-1837, 2018.

[12] H. Wu, P. Wu, F. S. Li, H. Shi, and K. Xu, "Fatigue analysis of the gearbox housing in high-speed trains under wheel polygonization using a multibody dynamics algorithm," Engineering Failure Analysis, vol. 100, pp. 351-364, 2019.

[13] Z. W. Wang, Y. Cheng, and G. M. Mei, “Torsional vibration analysis of the gear transmission system of high-speed trains with wheel defects," Proceedings of the Institution of $\mathrm{Me}$ chanical Engineers - Part F: Journal of Rail and Rapid Transit, vol. 234, no. 2, pp. 123-133, 2020.

[14] J. Zhang, G. X. Han, X. B. Xiao, W. Ruiqing, Y. Zhao, and X.-S. Jin, "Influence of wheel polygonal wear on interior noise of high-speed trains," Journal of Zhejiang University - Science, vol. 15, no. 12, pp. 1002-1018, 2014.

[15] X. W. Wu, S. Rakheja, W. B. Cai, M. Chi, A. K. W. Ahmad, and S. Qu, "A study of formation of high order wheel polygonalization," Wear, vol. 424, pp. 1-14, 2019. 
[16] W. M. Zhai, "Two simple fast integration methods for largescale dynamic problems in eng-ineering," International Journal for Numerical Methods in Engineering, vol. 39, no. 24, pp. 4199-4214, 1996.

[17] R. J. Guyan, "Reduction of stiffness and mass matrices," AIAA Journal, vol. 3, no. 2, p. 380, 1965.

[18] Z. S. Ren, G. Yang, S. S. Wang, and S. G. Sun, "Analysis of vibration and frequency transmission of high speed EMU with flexible model," Acta Mechanica Sinica, vol. 30, no. 6, pp. 876-883, 2014.

[19] W. M. Zhai, C. B. Cai, Q. C. Wang, and W. Lu, "Dynamic effects of vehicles on tracks in the case of raising train speeds," Proceedings of the Institution of Mechanical Engineers - Part F: Journal of Rail and Rapid Transit, vol. 215, no. 2, pp. 125-135, 2001.

[20] C. J. Yang, Y. Xu, W. D. Zhu, W. Fan, W. H. Zhang, and G. M. Mei, "A three-dimensional modal theory-based Timoshenko finite length beam model for train-track dynamic analysis," Journal of Sound and Vibration, vol. 479, Article ID 115363, 2020.

[21] A. Johansson, "Out-of-round railway wheels-assessment of wheel tread irregularities in train traffic," Journal of Sound and Vibration, vol. 293, no. 3-5, pp. 795-806, 2006.

[22] Y. G. Ye, D. C. Shi, P. Krause, Q. Tian, and T. Hecht, "Wheel flat can cause or exacerbate wheel polygonization," Vehicle System Dynamics, vol. 58, no. 10, pp. 1-30, 2019.

[23] X. W. Wu, W. B. Cai, M. R. Chi, L. Wei, H. Shi, and M. Zhu, "Investigation of the effects of sleeper-passing impacts on the high-speed train," Vehicle System Dynamics, vol. 53, no. 12, pp. 1902-1917, 2015.

[24] R. Dong, Vertical Dynamics of Railway Vehicle-Track System, Concordia University, Montreal, Canada, 1994.

[25] K. L. Knothe and S. L. Grassie, "Modelling of railway track and vehicle/track interaction at high frequencies," Vehicle System Dynamics, vol. 22, no. 3-4, pp. 209-262, 1993. 